\title{
Articles
}

\section{The effect of intense exercise on postprandial glucose homeostasis in Type II diabetic patients}

\author{
J.J.S. Larsen ${ }^{1}$, F. Dela ${ }^{1}$, S. Madsbad ${ }^{2}$, H. Galbo ${ }^{3}$ \\ ${ }^{1}$ Department of Medical Physiology, The Panum Institute, Copenhagen, Denmark \\ ${ }^{2}$ Department of Endocrinology, Hvidovre Hospital, Copenhagen, Denmark \\ ${ }^{3}$ The Copenhagen Muscle Research Centre, Rigshospitalet, Denmark
}

\section{Abstract}

Aims/hypothesis. The influence of postprandial high intensity exercise on glycaemia was studied in patients with Type II diabetes mellitus.

Methods. Patients who were treated by diet only $(n=8)$ ate a standardised breakfast and $4 \mathrm{~h}$ later a standardised lunch. They were studied in the resting state (control day) and on another day (exercise day) when they did intermittent exercised at high intensity after breakfast) (4 bouts including $3 \mathrm{~min}$ at $56.5 \pm 3.9 \% \dot{\mathrm{V}}_{\mathrm{O}_{2} \max }($ means $\pm \mathrm{SEM}), 4$ min at $98.3 \pm$ $5.1 \% \dot{\mathrm{V}}_{\mathrm{O}_{2} \max }$ and 6 min of rest). Responses were calculated as areas under the plasma concentration curve (AUC) during $4 \mathrm{~h}$ after either breakfast or lunch.

Results. Breakfast-AUCs for glucose, insulin and C peptide were lower $(p<0.05)$ on the exercise day compared with the control day (glucose: $538 \pm 94$ vs $733 \pm 64 \mathrm{mmol} \cdot 1^{-1} \cdot 240 \mathrm{~min}$; insulin: $16 \pm 4$ vs $22 \pm 3$ $\mathrm{pmol} \cdot \mathrm{ml}^{-1} \cdot 240 \mathrm{~min}$; C peptide: $143 \pm 22$ vs $203 \pm 29$ $\left.\mathrm{pmol} \cdot \mathrm{ml}^{-1} \cdot 240 \mathrm{~min}\right)$. After breakfast glucose ap- pearance was unaffected by exercise, whereas disappearance and clearance increased $(p<0.05)$. Muscle glycogen was diminished by exercise $(p<0.05)$. After lunch no differences were observed between experiments. Exercise-induced reductions in glucose, insulin and $\mathrm{C}$ peptide responses were similar $(p>0.05)$ in this study of intermittent, high intensity exercise and in a previous study of isocaloric but prolonged moderate (45 min at $53 \pm 2 \% \quad \dot{\mathrm{V}}_{\mathrm{O}_{2} \max }$ ) postprandial exercise.

Conclusion/interpretation. Postprandial high intensity exercise does not deteriorate glucose homeostasis but reduces both glucose concentrations and insulin secretion. The effect of exercise is related to energy expenditure rather than to peak exercise intensity. Finally, postprandial exercise does not influence glucose homeostasis during a subsequent main meal. [Diabetologia (1999) 42: 1282-1292]

Keywords Insulin sensitivity; physical activity; insulin; free fatty acids; glucose turnover.
Exercise is considered a cornerstone in the treatment of Type II (non-insulin-dependent) diabetes mellitus. In the postabsorptive state moderate exercise de-

Received: 7 May 1999 and in revised form: 5 July 1999

Corresponding author: Dr J.J. Larsen, MD, Department of Medical Physiology, The Panum Institute, Blegdamsvej 3, DK-2200 Copenhagen N, Denmark

Abbreviations: CD, Day with control experiment; ED, day with exercise; Ra, rate of appearance of glucose; Rd, rate of disappearance of glucose; B-AUC, area under curve $4 \mathrm{~h}$ after start of breakfast; L-AUC, area under curve $4 \mathrm{~h}$ after start of lunch; 3-[ $\mathrm{H}]$-glucose, tritiated glucose in carbon position three. creases the plasma glucose concentration and is followed by increased insulin sensitivity [1-5]. Patients, exercise, however, mostly in the postprandial rather than in the postabsorptive state. Accordingly we recently studied the effects of moderate exercise (45 min at $53 \% \dot{\mathrm{V}}_{\mathrm{O}_{2} \text { max }}$ ) in the postprandial state [6]. We found that moderate exercise decreases plasma glucose concentration in patients with mild Type II diabetes also in this state [6]. If exercise was substituted by a reduction of the energy content of the meal equivalent to the energy requirements of exercise, the overall diminution of the postprandial concentrations of glucose, insulin and $\mathrm{C}$ peptide were the same as in experiments with exercise and normocaloric 
meals. We proposed therefore that exercise-induced reductions in glucose concentrations and insulin secretion are closely related to the overall energy expenditure [6]. Surprisingly, exercise in the postprandial state did not influence glucose and insulin responses to a subsequent meal [6]. A postexercise increase in glucose clearance is known, however, to be closely related to a reduced glycogen content in muscle [7-9], and we hypothesised that muscle glycogen was not depleted at the meal after exercise [6].

Severe exercise elicits an exaggerated counterregulatory hormonal response in Type II diabetic patients [10], which could explain why in the postabsorptive state severe exercise, in contrast to moderate exercise, deteriorates glucose homeostasis both during exercise and in the early recovery period after exercise [10]. Severe exercise is, compared with moderate exercise, also accompanied, however, by relatively high glycogen depletion in the working muscle [11]. To extend existing knowledge concerning the relation between food intake, exercise and glucoregulation, we have now studied Type II diabetic patients during severe exercise (peak intensity $98 \% \dot{\mathrm{V}}_{\mathrm{O}_{2} \max }$ ) in the postprandial state. The specific aims were to study if severe exercise in the postprandial state causes an immediate aggravation of glucose homeostasis as seen in the postabsorptive state [10] or whether, conversely, glucose homeostasis is improved as seen in response to moderate exercise [6]. In the latter case reductions in glucose concentrations might be closely associated with overall energy expenditure or rather reflect the exercise intensity. To be able to distinguish between these possibilities the applied high intensity intermittent exercise protocol was designed to yield the same overall amount of work done as the prolonged moderate exercise protocol used in our previous study ("isocaloric exercise"), in which meals were also identical to those used in the present study [6].

\section{Materials and methods}

Subjects. Sedentary Type II diabetic men $(n=8)$, who were treated by diet only (fasting plasma glucose concentrations: $9.1 \pm 0.5 \mathrm{mmol} \cdot \mathrm{l}^{-1}$ (means $\left.\pm \mathrm{SEM}\right) ; \mathrm{HbA}_{1 \mathrm{c}}: 6.0 \pm 0.3 \%$; age: $56 \pm 2$ years; weight: $93.5 \pm 4.9 \mathrm{~kg}$; BMI: $29.2 \pm 1.2 \mathrm{~kg} \cdot \mathrm{m}^{-2}$ and $\dot{\mathrm{V}}_{\mathrm{O}_{2} \text { max }}: 29 \pm 2 \mathrm{ml} \cdot \mathrm{min}^{-1} \cdot \mathrm{kg}^{-1}$ ) and who met the current criteria of the World Health Organisation Classification of Diabetes Mellitus (fasting venous plasma glucose $>7.0 \mathrm{mmol} \cdot \mathrm{l}^{-1}$ and plasma glucose $>11.1 \mathrm{mmol} \cdot \mathrm{l}^{-1} 120 \mathrm{~min}$ after an oral intake of $75 \mathrm{~g}$ glucose) participated in the study. The number of subjects exceeds the number ordinarily included in detailed physiological studies. No women were included because the relation between metabolic response and exercise intensity could depend on sex $[12,13]$, which could have blurred the conclusions of the study. All subjects had normal cardiovascular, renal, hepatic, gastrointestinal and neurological functions as assessed by clinical examination, ECG, blood pressure and standard laboratory blood tests. None of the patients were exercis- ing on a regular basis. After careful explanation of the nature, purpose and possible risks involved in the study informed consent was obtained. The local municipal ethics committee approved the study.

Pre-study evaluation. On 7-11 days before to the first metabolic study the individual relation between work load and oxygen consumption $\left(\dot{\mathrm{V}}_{\mathrm{O}_{2} \max }\right.$ ) was determined as described previously [6]. From these data, the workloads requiring $50 \% \dot{\mathrm{V}}_{\mathrm{O}_{2} \max }$ and $100 \% \dot{\mathrm{V}}_{\mathrm{O}_{2} \max }$ were estimated for each subject.

Experimental protocol. The study included two separate days of investigation; one day on which the subjects were resting throughout the experiment (CD), and another day on which the subjects exercised in four intermittent bouts for $46 \mathrm{~min}$ starting 45 min after they had begun eating breakfast (ED). Experiments were separated by at least 14 days and conducted in random order. The subjects always arrived in the laboratory at 06.45 hours after an overnight fast, were weighed and thereafter asked to rest in bed in a supine position. One cannula was inserted in a dorsal antebrachial vein for primed infusion of 3$\left[{ }^{3} \mathrm{H}\right]$-glucose [14] as described previously [6]. Another cannula was inserted in the contralateral arm in the retrograde direction in a dorsal hand vein for drawing of arterialized blood [6]. After a 2-h tracer equilibration period the breakfast meal was served. It contained $29 \mathrm{~kJ} \cdot \mathrm{kg}^{-1}$ body weight (56\% carbohydrate $(\mathrm{CHO}), 30 \%$ fat and $14 \%$ protein). Intake of breakfast was completed within $20 \mathrm{~min}$. A lunch meal was served $\left(59 \mathrm{~kJ} \cdot \mathrm{kg}^{-1}\right.$ body weight, $53 \%$ carbohydrate (CHO), $31 \%$ fat and $16 \%$ protein) $4 \mathrm{~h}$ after the start of breakfast. During the equilibration period and until $4 \mathrm{~h}$ after serving the lunch meal, blood was sampled at intervals. Urine was collected and its volume measured immediately after the subjects arrived in the laboratory, before breakfast and lunch and $4 \mathrm{~h}$ after lunch. Urine for determination of urea was stored immediately at $-20^{\circ} \mathrm{C}$. Expiatory gas was collected in Douglas bags for $5 \mathrm{~min}$ at $15 \mathrm{~min}$ before breakfast and at 35, 65 (CD only), 85 (CD only) and 230 min after the start of breakfast and at 35, 65, 85 and $230 \mathrm{~min}$ after lunch. The subjects had breathed through the mouthpiece $3 \mathrm{~min}$ in advance. Throughout the intermittent exercise period expiratory gas concentrations and flow were continuously measured by an Ergo-Oxy Screen [15].

On ED subjects had four ergometer cycle rides interrupted by 6 min resting periods spent sitting on the ergometer. Each exercise bout consisted of $3 \mathrm{~min}$ at a load previously determined to require about $50 \%$ of $\dot{\mathrm{V}}_{\mathrm{O}_{2} \max }$ ("warm up") followed by $4 \mathrm{~min}$ at a load previously determined to require about $100 \%$ of $\dot{\mathrm{V}}_{\mathrm{O}_{2} \max }$. This protocol was designed to yield the same overall amount of work done as the prolonged moderate exercise protocol used in our previous study (45 min of continuous exercise at $53 \%$ of $\dot{\mathrm{V}}_{\mathrm{O}_{2} \max }$ [6]).

Blood and muscle biopsy sampling. Blood was sampled, stabilised and centrifuged and plasma stored as described previously [6]. Before breakfast and lunch meals muscle biopsies were taken from the vastus lateralis portion of the quadriceps muscle approximately one-third the distance from the superior margin of the patella to the anterior iliac spine. Skin and fascia were anaesthetised with $3-5 \mathrm{ml}$ of lidocain $(10 \mathrm{mg} / \mathrm{ml})$ and biopsies were taken through a $10-\mathrm{mm}$ long incision using a Bergström needle and suction.

Analyses and calculations. All glucose and lactate analyses were done immediately after plasma separation by the fixed glucose oxidase and lactate oxidase methods, respectively, using an automatic glucose analyser (YSI Model 2300 STAT PLUS, Yellow Springs Instruments, Yellow Springs, Ohio, 
USA). For the assay of $3-\left[{ }^{3} \mathrm{H}\right]$-glucose radioactivity $1 \mathrm{ml}$ plasma samples were immediately deproteinized with $500 \mu \mathrm{l} 1 \mathrm{~N}$ perchloric acid. Duplicate aliquots $(500 \mu \mathrm{l})$ of the supernatant were evaporated under a stream of dry air to remove tritiated water. The dry residue was dissolved in $200 \mu \mathrm{l}$ water and counted with $3 \mathrm{ml}$ scintillation liquid [6]. The glucose pool (distribution space $\times$ plasma concentration), the rates of appearance ( $\mathrm{Ra})$ and disappearance $(\mathrm{Rd})$ of plasma glucose in the basal state and glucose kinetics during non-steady state conditions were calculated as described previously [6].

All samples from one subject were always analysed in the same assay run. Commercially available ELISA kits (Dako, Cambridge, UK) based on two monoclonal antibodies were used for determination of plasma concentrations of insulin and $\mathrm{C}$ peptide. Catecholamines were determined by a singleisotope radioenzymatic assay [16]. Using enzymatic fluorometric methods plasma concentrations of NEFA and glycerol were determined [17]. Urea concentrations in plasma and urine were determined spectrophotometrically after addition of a reagent containing urease (Sigma kit, Sigma Diagnostics, St. Louis, Mo., USA) [18]. Hematocrit was measured by the microhematocrit method. At rest expired air was analysed for $\mathrm{O}_{2}$ and $\mathrm{CO}_{2}$ by paramagnetic (Servomex OA 189, Crowborough, Sussex, UK) and infrared (Capnograph Godard 146, Bilthoven, The Netherlands) gas meters, respectively and volume was measured in a $150 \mathrm{~L}$ spirometer (Warren E. Collins incorporated, Braintree, Mas., USA).

Muscle samples were quick-frozen in liquid freon maintained at its freezing point with liquid nitrogen. The samples were then stored in liquid nitrogen until analysis. Analysis of glycogen content was done as described previously [17] after samples had been freeze-dried and nonmuscle constituents (blood and connective tissue) removed by dissection under a microscope.

Incremental areas under the plasma concentration compared with time curve (AUC) for glucose, insulin and C peptide were calculated for 4-h periods by the trapezoid method from the last prebreakfast (B-AUC) and prelunch (L-AUC) values, respectively. Net areas are presented, areas below premeal values having been subtracted from areas above. Conclusions were, however, identical to those based on gross incremental areas above premeal values or on overall areas above the $\mathrm{X}$-axis. Calculations of whole body glucose oxidation and storage, lipid oxidation and lipid synthesis were done according to [19].

Statistical analysis. Differences over time were evaluated by a two-way repeated measures analysis of variance. When significant $F$ ratios were obtained, the student-Newman-Keuls test was used as a test after this to locate the significant differences. The paired Student's $t$ test was used to evaluate differences between single data on CD and ED. The Student's $t$ test for unpaired data was used to test if data differed between this study and our previous study [6] on different subjects. The significance level was 0.05 in two-tailed testing.

\section{Results}

Glucose, insulin and $C$ peptide responses. Fasting plasma concentrations of glucose, insulin and C peptide were identical on the two experimental days $(p>0.05)$. Concentrations of glucose, insulin and C peptide always increased in response to both breakfast and lunch meals $(p<0.05)$. Compared with con- trol experiments exercise interrupted, however, the increase seen after breakfast in all three variables (Fig.1). Overall both plasma glucose (from $12.6 \pm 0.7$ to $11.4 \pm 0.8 \mathrm{mmol} \cdot \mathrm{l}^{-1}$ ) and insulin (from $144 \pm 27$ to $93 \pm 21 \mathrm{pmol} \cdot \mathrm{l}^{-1}$ ) concentrations decreased considerably during the $45 \mathrm{~min}$ of exercise $(p<0.05)$. In response to each single exercise bout glucose concentrations did not change $(p>0.05)$, whereas a decrease in both insulin and $\mathrm{C}$ peptide concentrations $(p<0.01)$ followed by rebound increases $(p<0.01)$ was seen (Fig. 2$)$. Confirming that post-breakfast glycaemia and insulin secretion were attenuated by exercise, B-AUCs for glucose, insulin and $\mathrm{C}$ peptide were lower on ED compared with $\mathrm{CD}(p<0.05)$ (Fig. 3). In response to lunch glucose, insulin and $\mathrm{C}$ peptide concentrations increased identically on the two experimental days (Fig.1) and also L-AUCs were identical $(p>0.05)$ (Fig. 2).

The exercise-induced reductions in areas under curve for glucose, insulin and $\mathrm{C}$ peptide concentrations during and 4 and $8 \mathrm{~h}$ after breakfast were similar in this study of high intensity intermittent exercise and in our previous investigation of postprandial, prolonged moderate but isocaloric exercise [6] (glucose reductions calculated for the $8 \mathrm{~h}$-period: $267 \pm 108$ vs $273 \pm 121 \mathrm{mmol} \cdot \mathrm{l}^{-1} \cdot 480 \mathrm{~min}$, $p>0.05$ ) (Fig. 4).

Glucose kinetics. The rate of appearance ( $\mathrm{Ra}$ ) of glucose in plasma always increased in response to breakfast and postprandial $\mathrm{Ra}$ was not affected in the exercise period ( $p>0.05)$ (Fig. 5). In contrast, during the exercise period both glucose disappearance and clearance were increased when compared with the control day (Rd: $4.5 \pm 0.5$ vs $3.3 \pm$ $0.3 \mathrm{mg} \cdot \mathrm{min}^{-1} \cdot \mathrm{kg}^{-1}, p<0.05$; clearance: $2.2 \pm 0.4 \mathrm{vs}$ $\left.1.5 \pm 0.2 \mathrm{ml} \cdot \mathrm{min}^{-1} \cdot \mathrm{kg}^{-1}, p<0.05\right)$. In the period after exercise and until lunch average $\mathrm{Ra}$ was increased when compared with control experiments $(3.4 \pm 0.3$ vs $\left.2.6 \pm 0.2 \mathrm{mg} \cdot \mathrm{min}^{-1} \cdot \mathrm{kg}^{-1}, p<0.05\right)$. Average $\mathrm{Rd}$ and clearance were also higher on ED compared to $\mathrm{CD}$ but this difference did not attain statistical significance (Rd: $3.8 \pm 0.4$ vs $3.3 \pm 0.2 \mathrm{mg} \cdot \mathrm{min}^{-1} \cdot \mathrm{kg}^{-1}$, $p>0.05$; clearance: $1.9 \pm 0.3$ vs $1.6 \pm 0.1 \mathrm{ml}$. $\left.\mathrm{min}^{-1} \cdot \mathrm{kg}^{-1}, p>0.05\right)$. After lunch $\mathrm{Ra}, \mathrm{Rd}$ and clearance did not differ between CD and ED. Accordingly, integrated glucose delivery to plasma, and integrated tissue glucose uptake also did not differ for $4 \mathrm{~h}$ during and after lunch between exercise and control experiments (glucose delivery: $542 \pm 35 \mathrm{mmol}$ vs $560 \pm 30 \mathrm{mmol} ; \quad$ glucose uptake: $520 \pm 33$ vs $534 \pm 34 \mathrm{mmol}, p>0.05)$.

Lactate, glycerol and NEFA concentrations. Lactate concentrations only increased a little with meals but were greatly increased by exercise $(p<0.05)$ (Figs. 3, $6)$. After lunch lactate concentrations did not differ between experiments $(p>0.05)$. On CD glycerol and 

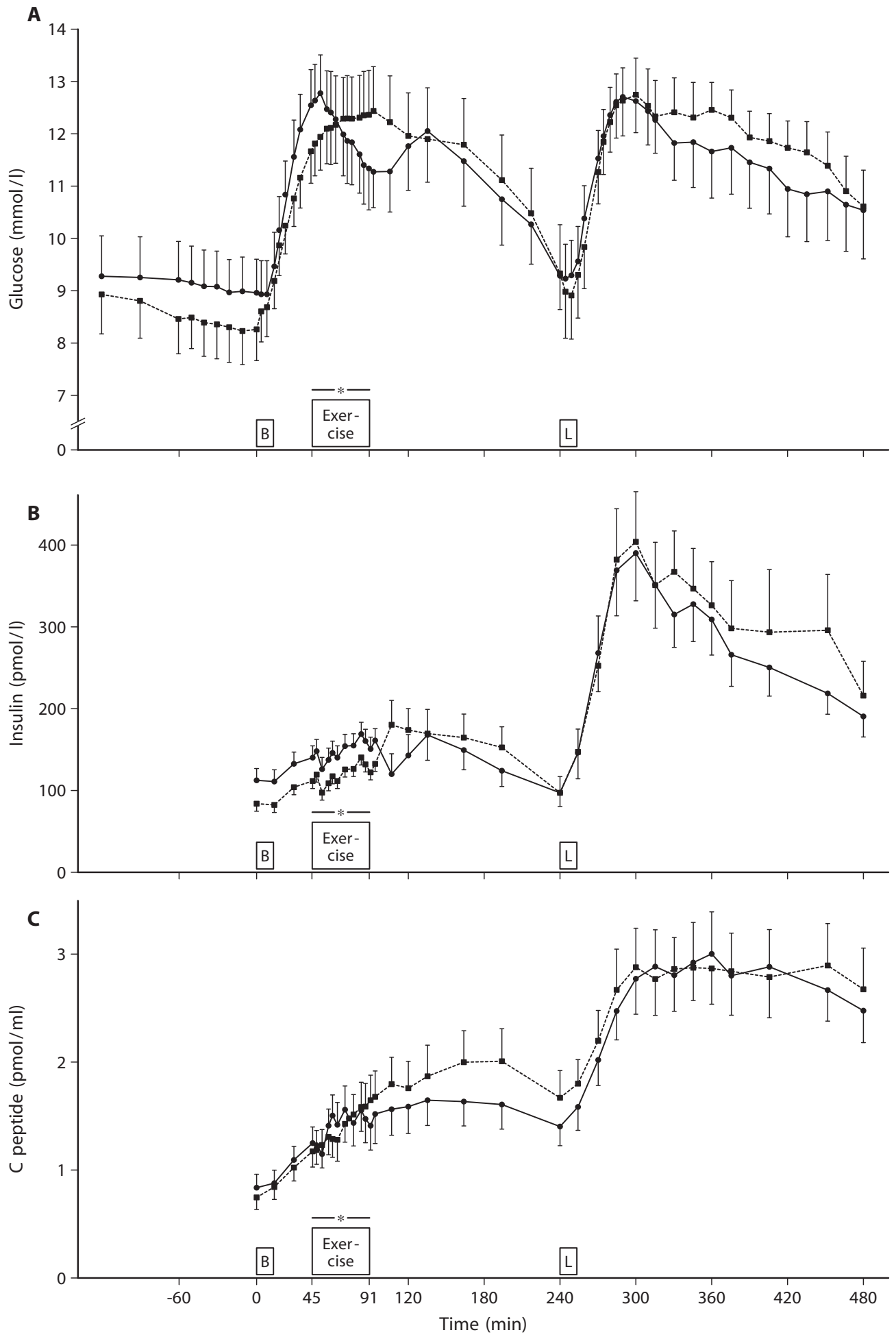

Fig.1 A-C. Plasma glucose (A), insulin (B) and C peptide (C) concentrations in eight Type II diabetic patients studied on two occasions: control day (CD) (ロ and exercise day (ED) (O). Breakfast (B) was taken at time 0 min, and lunch (L) at time $240 \mathrm{~min}$ on both days. Exercise was in 4 bouts for $46 \mathrm{~min}$ from time $45 \mathrm{~min}$ (each bout including $3 \mathrm{~min}$ at $57 \pm 4 \% \dot{\mathrm{V}}_{\mathrm{O}_{2} \max }$ and 4 min at $98 \pm 5 \% \dot{\mathrm{V}}_{\mathrm{O}_{2} \max }$ and followed by 6 min of rest). Values are means \pm SEM. During exercise on ED average plasma glucose, insulin and $\mathrm{C}$ peptide concentrations were lower than on $\mathrm{CD}(p<0.05)$. For the exercise period, see also Fig. 3
NEFA concentrations varied opposite to those of insulin in response to meals (Fig. 6). Exercise counteracted the breakfast-induced decreases in these concentrations. Glycerol concentrations continuously increased in response to exercise $(p<0.05)$ whereas NEFA concentrations decreased during exercise $(p<0.001)$ but showed pronounced increases during rest periods in between exercise bouts $(p<0.001)$. 

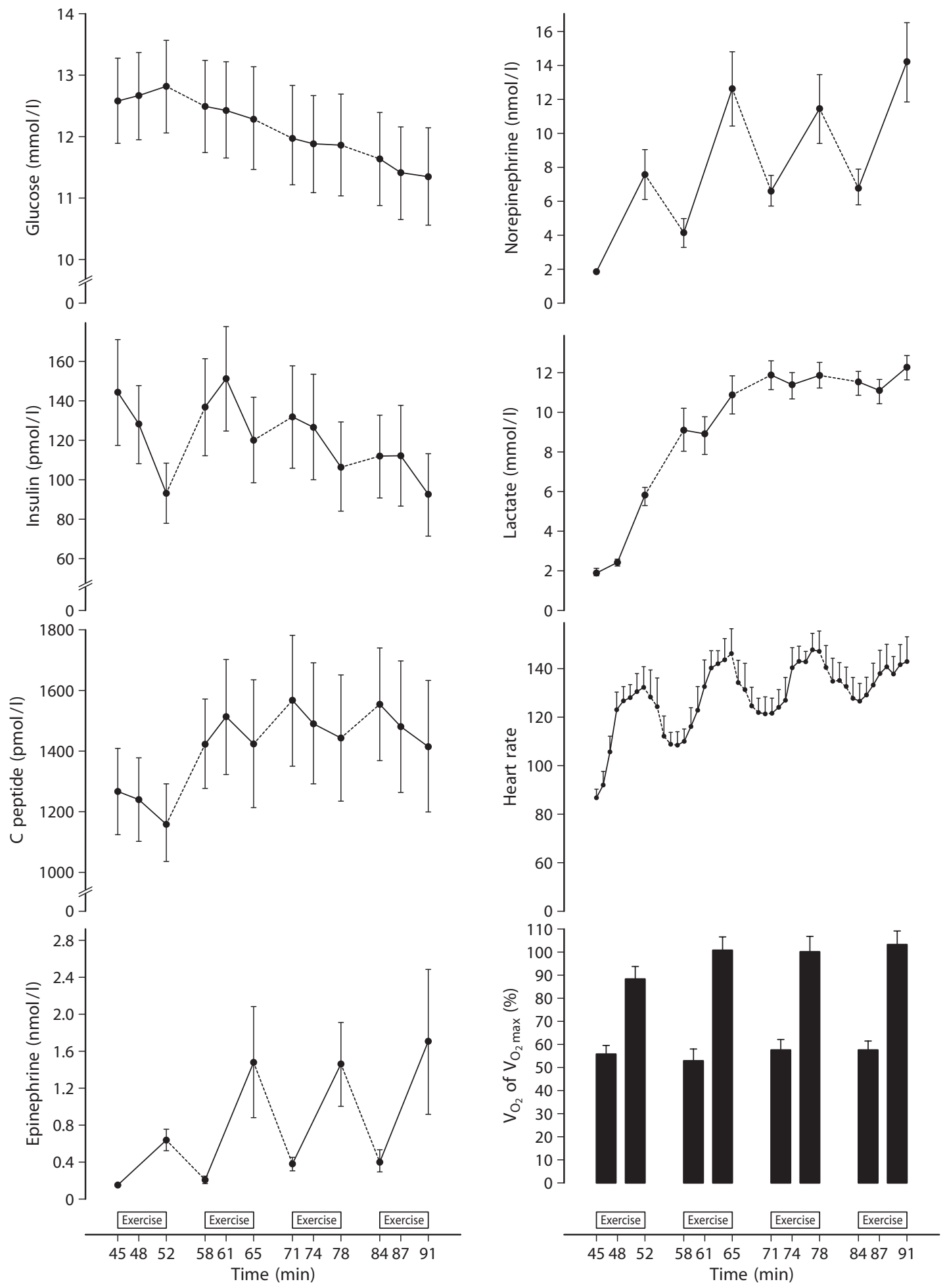

Fig. 2. Concentrations of hormones and substrates in response to severe intermittent exercise in eight postprandial Type II diabetic patients. Heart rate and $\dot{\mathrm{V}}_{\mathrm{O}_{2}}$ in percent of $\dot{\mathrm{V}}_{\mathrm{O}_{2} \max }$ are also shown. Exercise began 45 min after start of breakfast and consisted in 4 bouts of $3 \mathrm{~min}$ at moderate and $4 \mathrm{~min}$ at severe intensity (full drawn line), each followed by 6 min of rest (broken line). Values are means \pm SEM

During and after lunch glycerol and NEFA concentrations did not differ between experiments $(p<0.05)$.

Catecholamine responses. Fasting epinephrine and norepinephrine concentrations were similar on $\mathrm{CD}$ and ED (epinephrine: $0.13 \pm 0.02$ vs $0.15 \pm 0.02$ $\mathrm{nmol} \cdot \mathrm{l}^{-1}, \quad p>0.05 ; \quad$ norepinephrine $1.6 \pm 0.3$ vs $1.8 \pm 0.2 \mathrm{nmol} \cdot \mathrm{l}^{-1}, p>0.05$, respectively) (Fig. 3). On 

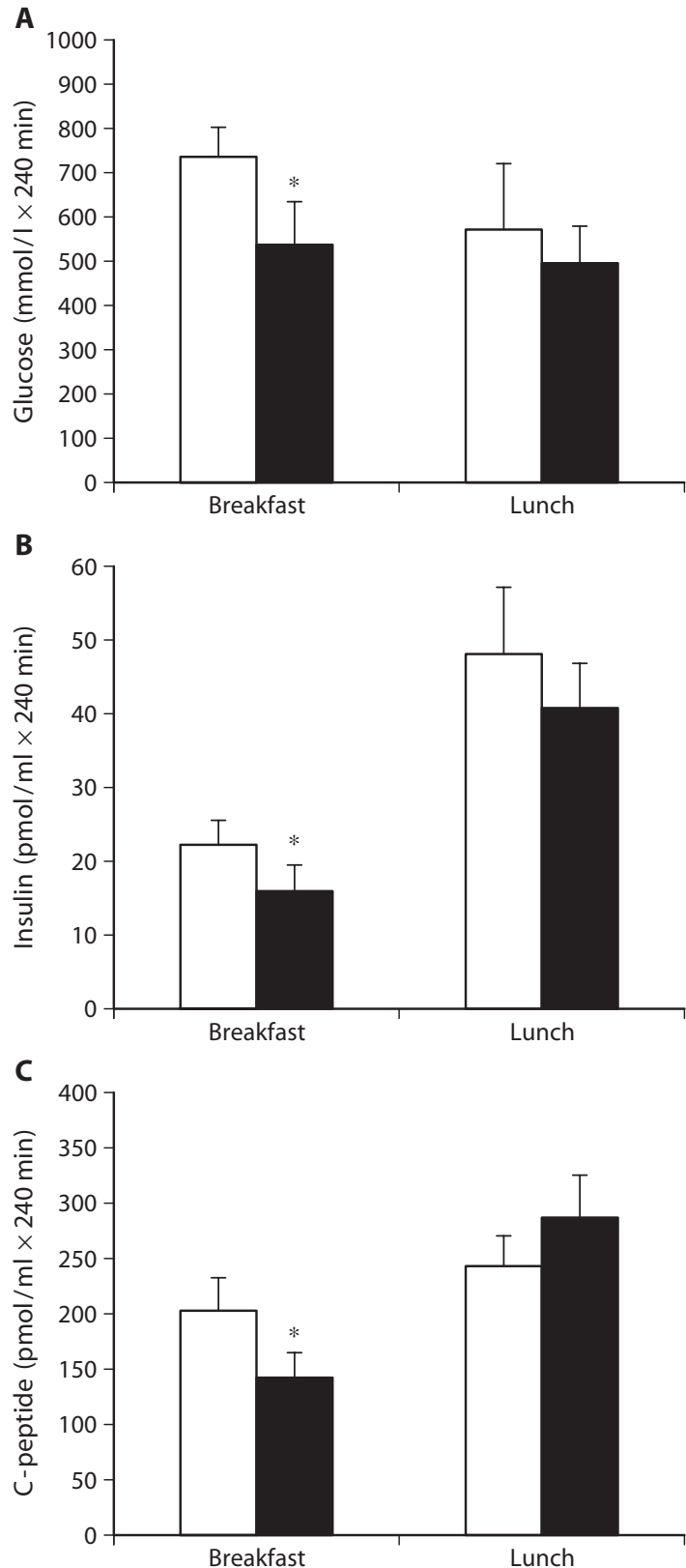

Fig. 3 A-C. Incremental area under curve (AUC) for glucose $(\mathbf{A})$, insulin (B) and C peptide (C) in eight Type II diabetic patients studied at two occasions; control day (CD) $(\square)$ and exercise day (ED) ( $\square$ ). Breakfast was taken by the subjects at 0 min and lunch at 240 min on both days. Breakfast AUC was calculated from 0 min to $240 \mathrm{~min}$. Lunch AUC was calculated from $240 \mathrm{~min}$ to $480 \mathrm{~min}$. Exercise was undertaken from 45 to 91 min after start of breakfast. $* p<0.05$, difference in comparison to $\mathrm{CD}$

CD catecholamine concentrations were constant throughout the study (data not shown). On ED both epinephrine and norepinephrine increased considerably in response to exercise $(p<0.05)$.

Oxidation data. The $\dot{\mathrm{V}}_{\mathrm{O}_{2}}$ was $2.8 \pm 0.3 \mathrm{ml} \cdot \mathrm{kg} \cdot \mathrm{min}^{-1}$ at rest and increased to $16.2 \pm 1.5$ at moderate and $28.0 \pm 2.1 \mathrm{ml} \cdot \mathrm{kg} \cdot \mathrm{min}^{-1}$ at severe exercise, corre-
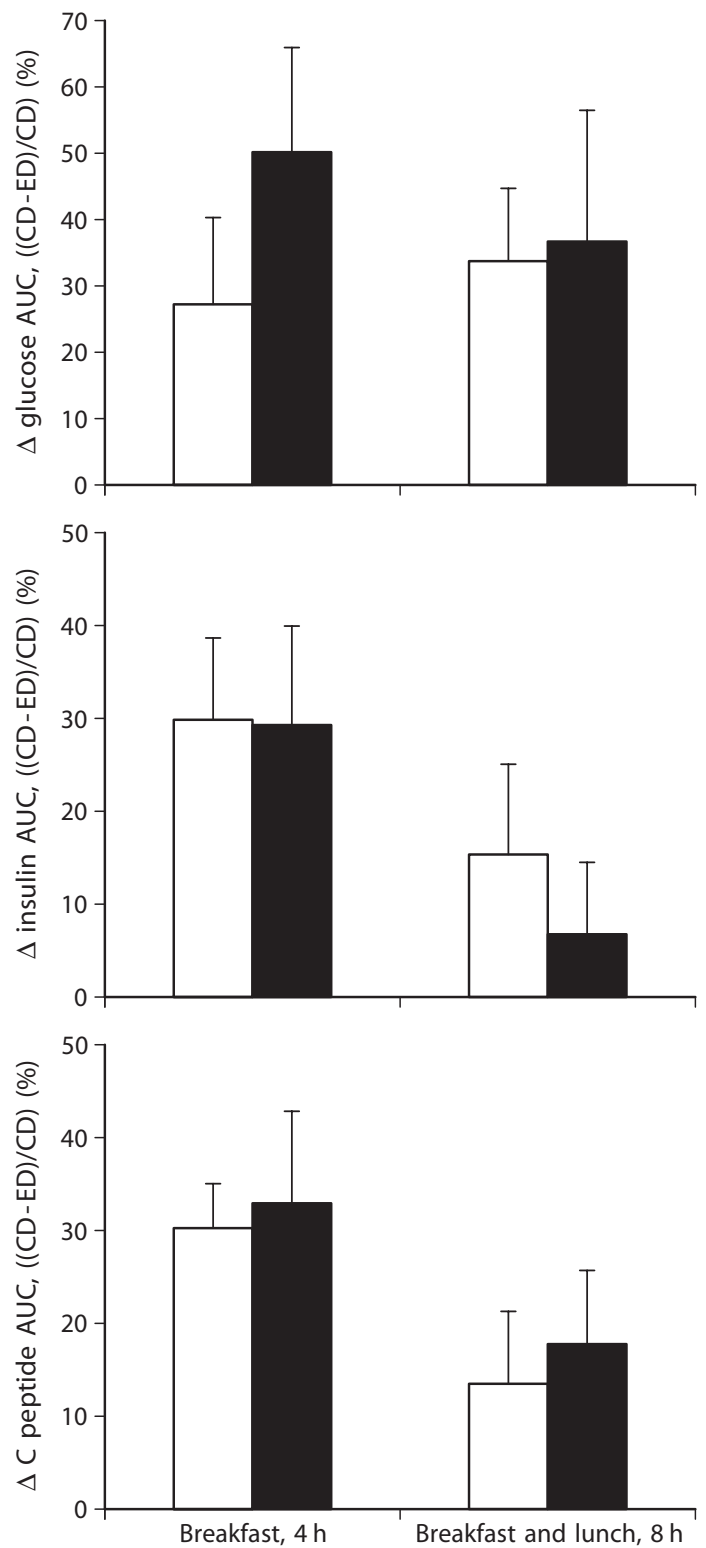

Fig. 4. Exercise-induced reductions in incremental areas under curve for glucose, insulin and $\mathrm{C}$ peptide concentrations during and $4 \mathrm{~h}$ after breakfast ("Breakfast, $4 \mathrm{~h}$ ") as well as during an $8 \mathrm{~h}$ period including both breakfast and lunch ("Breakfast and lunch, 8 h") in Type II diabetic patients. Data from two studies are shown. In this study ( $\square$ ) 45-91 min after start of breakfast eight diabetic patients either did intense intermittent exercise (ED) or rested (CD). In a previous study (ם) [6] 45-90 min after start of breakfast eight other diabetic patients either did moderate, prolonged exercise (ED) or rested (CD). The two exercise protocols were isocaloric and the breakfast and lunch meals were identical in the two studies. Furthermore, the two groups of diabetic patients were similar in age, sex, weight, duration and treatment of diabetes and $\dot{\mathrm{V}}_{\mathrm{O}_{2} \max }$. The reason that the effect of exercise is expressed in \% rather than in absolute units is that insulin and $\mathrm{C}$ peptide concentrations were determined with ELISA and RIA in this and in the former study, respectively. No difference was found between the two studies $(p>0.05)$ 

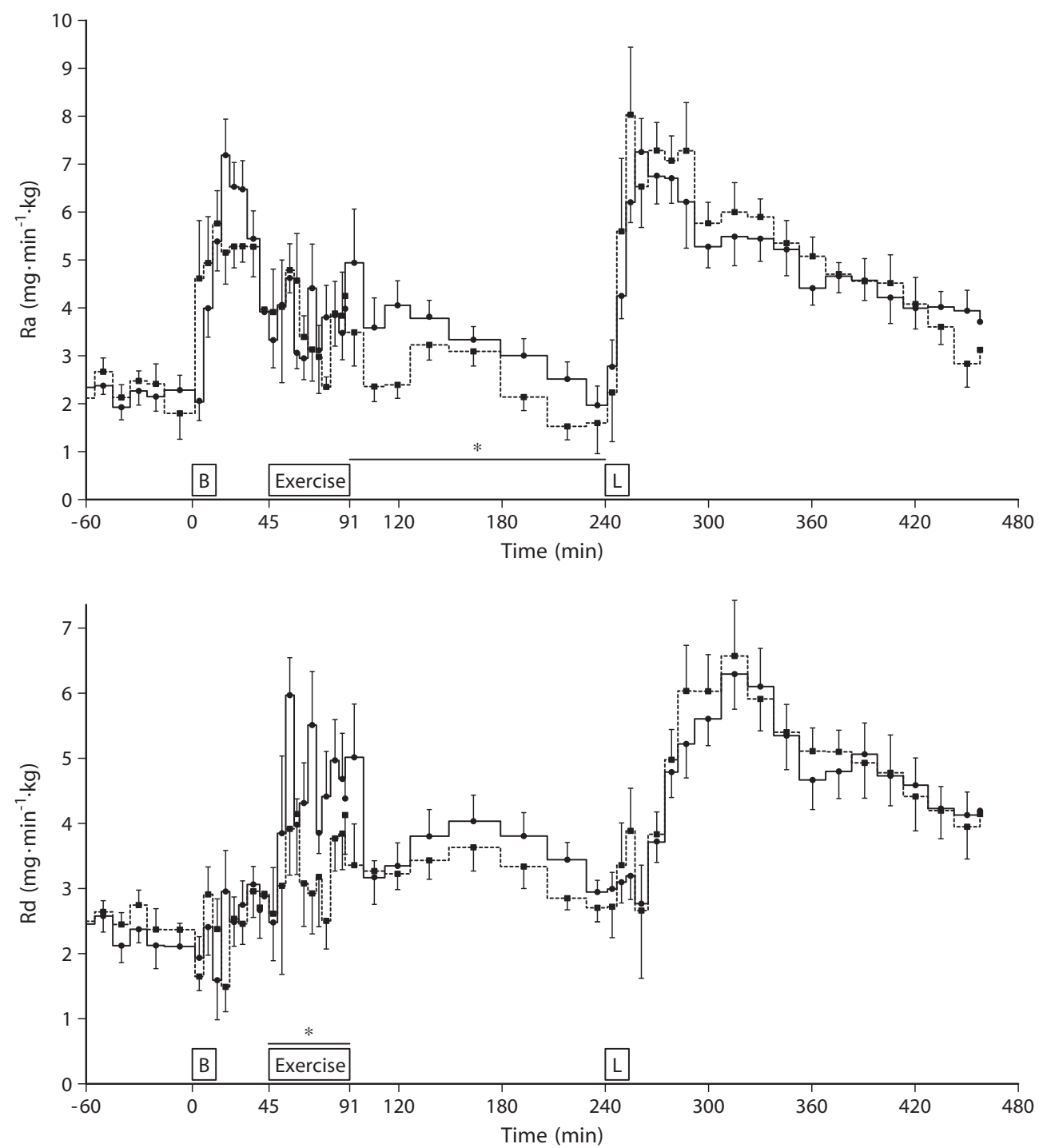

Fig.5. Rate of appearance $(\mathrm{Ra})$ and rate of disappearance (Rd) of plasma glucose in eight Type II diabetic patients studied on two occasions: control day (CD) ( $-\square)$ and exercise day (ED) (- Breakfast (B) was taken at time $0 \mathrm{~min}$, and lunch (L) at time $240 \mathrm{~min}$ on both days. On ED intermittent severe exercise was done for $45 \mathrm{~min}$. Values are means \pm SEM. During the exercise period average $\mathrm{Rd}$ was higher than in the corresponding period on $\mathrm{CD}(p<0.05)$. In the period between exercise and lunch average $\mathrm{Ra}$ was higher than in the corresponding period on CD $(p<0.05)$. For further explanation, see Fig. 1

sponding to $57 \pm 4 \%$ and $98 \pm 5 \% \dot{\mathrm{V}}_{\mathrm{O}_{2} \max }$, respectively (Fig.3). Throughout the study glucose, lipid and protein oxidation rates were similar between the two days of investigation except during the $45 \mathrm{~min}$ of exercise on ED. During exercise estimated oxidation of carbohydrate and lipid increased significantly from $0.11 \pm 0.03$ and $0.10 \pm 0.01 \mathrm{~g} \cdot \mathrm{min}^{-1}$ at time $-15 \mathrm{~min}$, respectively to $0.71 \pm 0.04 \mathrm{~g} \cdot \mathrm{min}^{-1}$ and $0.46 \pm 0.03 \mathrm{~g} \cdot \mathrm{min}^{-1}$ at moderate loads $(p<0.05)$ and to $2.73 \pm 0.12 \mathrm{~g} \cdot \mathrm{min}^{-1}$ and $0.46 \pm 0.08 \mathrm{~g} \cdot \mathrm{min}^{-1}$ at the severe loads $(p<0.05)$. Total carbohydrate expenditure during the $46 \mathrm{~min}$ of intermittent exercise was $54.7 \pm 3.4 \mathrm{~g}$ corresponding to $56.0 \pm 4.0 \%$ of the carbohydrate eaten during breakfast. Estimated protein oxidation was unaffected by exercise. In the period after exercise and before lunch glucose oxidation did not differ from values on $\mathrm{CD}(p>0.05)$.

Muscle glycogen. Before breakfast muscle glycogen concentrations were similar on $\mathrm{CD}$ and ED (438 \pm 28 vs $401 \pm 24 \mathrm{mmol}$ glycosyl units $\cdot \mathrm{kg}^{-1}$ dry wt, respectively, $p>0.05)$. On CD pre-lunch glycogen content $\left(452 \pm 23 \mathrm{mmol}\right.$ glycosyl units $\cdot \mathrm{kg}^{-1}$ dry wt) was identical to pre-breakfast values $(p>0.05)$. In contrast on ED the pre-lunch concentration $\left(296 \pm 38 \mathrm{mmol}\right.$ glycosyl units $\cdot \mathrm{kg}^{-1}$ dry wt) was reduced by $27 \pm 9 \%$ compared with the pre-breakfast values $(p<0.05)$. 

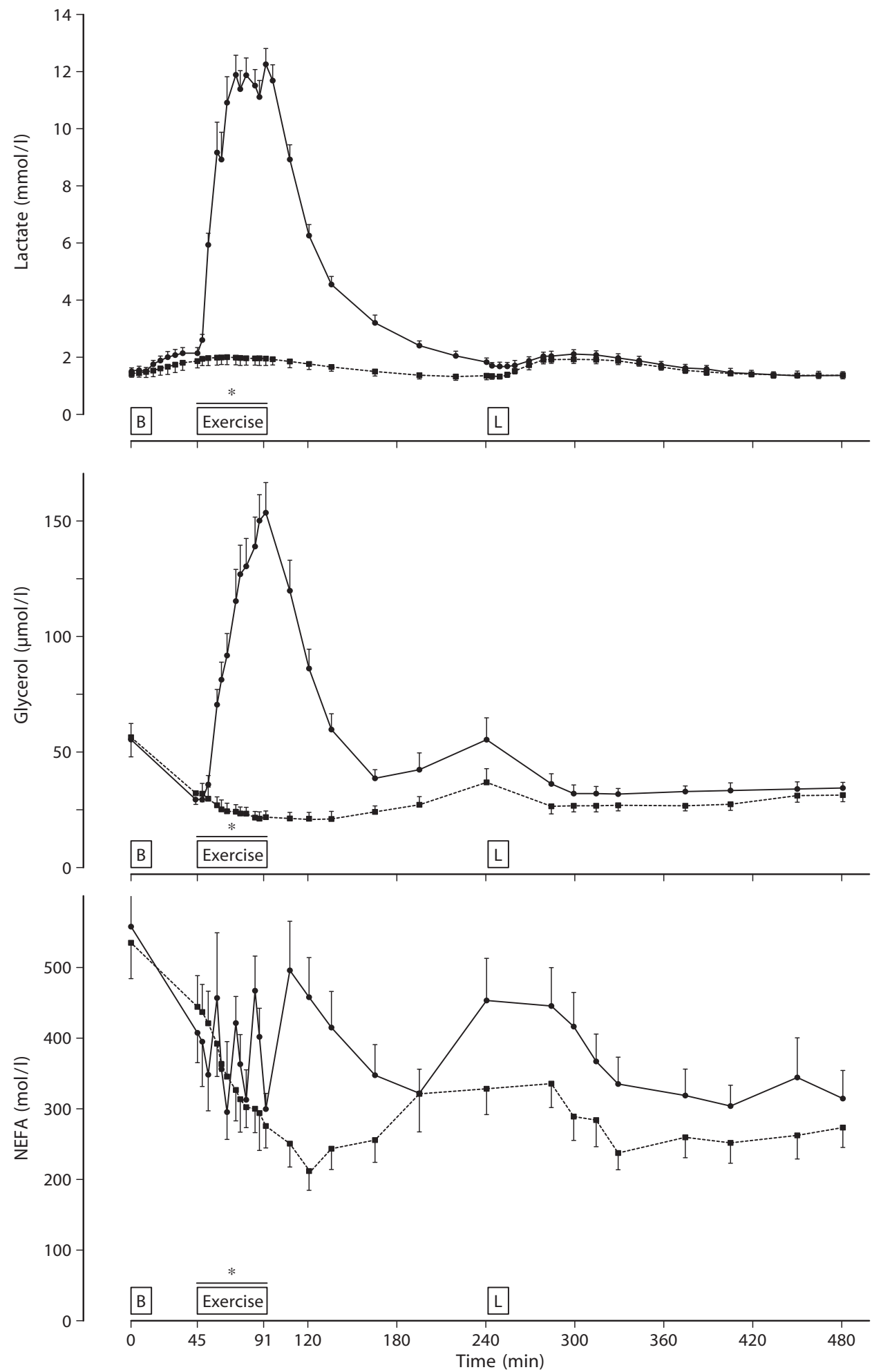

Fig. 6. Plasma lactate, glycerol and NEFA concentrations in plasma in eight Type II diabetic patients studied on two occasions; control day (CD) ( $\square$ ) and exercise day (ED) (O). Breakfast (B) was taken at time 0 min and lunch (L) at time $240 \mathrm{~min}$ on both days. On ED intermittent severe exercise was done for $45 \mathrm{~min}$. Values are means \pm SEM. During exercise on ED average plasma lactate, glycerol and NEFA concentrations were higher than on $\mathrm{CD}(p<0.05)$

\section{Discussion}

The major finding in this study was that in contrast to findings in the postabsorptive state [6], postprandial severe exercise does not deteriorate glucose homeostasis. In contrast, intermittent, high intensity exercise reduces both glucose concentrations and insulin secretion after a meal. The decrease in glucose con- 
centrations reflects that exercise increases plasma glucose clearance. The effect of exercise is closely related to overall energy expenditure rather than to the intensity of exercise. Postprandial high intensity intermittent exercise is accompanied by muscle glycogen breakdown but does not influence glucose homeostasis during a subsequent main meal.

It has previously been shown in Type II diabetic patients that during severe exercise in the postabsorptive state glucose production is greater than tissue glucose uptake and accordingly plasma glucose concentrations increase [10]. This is probably due to an exaggerated counterregulatory hormonal response [10]. The exercise intensity and lactate concentrations in that study of postabsorptive exercise were similar to those in our study of postprandial exercise [10]. Nevertheless, in our study glucose concentrations did not increase in response to exercise and cathecholamine concentrations increased less than in our earlier study (Fig.3) [6]. These findings probably reflect that the counterregulatory hormonal response to exercise depends on the nutritional state [20-23] and that, furthermore, the high glucose and insulin concentrations accompanying food intake inhibit an exercise induced increase in hepatic glucose production (Figs. 1, 5) [6, 20, 24, 25]. In contrast, even during breakfast severe exercise caused considerable increases in glycerol and NEFA concentrations (Fig. 6). This observation is in line with findings during moderate exercise [6]. Despite insulin secretion being stimulated by the breakfast meal the concentrations of both insulin and $\mathrm{C}$ peptide decreased during each exercise bout (Figs. 1-3). This probably reflected that beta-cell secretion was depressed by increased sympathetic nerve activity [20]. In accordance with this view insulin and $\mathrm{C}$ peptide concentrations showed rebound increases between exercise bouts and always varied inversely with plasma catecholamine concentrations (Fig. 3).

Overall, the intermittent, high intensity exercise regimen used in our study diminished the plasma glucose response to breakfast (Figs. 1,2). The effect was exerted during the exercise period and in the early recovery period and reflected an enhanced tissue glucose uptake and clearance (Figs. 1, 5). Exercise increases muscle glucose clearance by an increase in muscle blood flow, recruitment of muscle capillaries and glucose transporters, by an increase in muscle metabolic rate and by increasing insulin sensitivity $[20,26,27]$. In our study $55 \pm 3 \mathrm{~g}$ carbohydrate were oxidized during exercise corresponding to $56.0 \pm 4.0 \%$ of the carbohydrate eaten during breakfast. Exercise has previously been shown to enhance the oxidation of an oral glucose load in healthy subjects [28-30]. The exercise induced increase in glucose clearance and reduction in overall post-breakfast glucose response occurred in the face of a decrease in insulin concentrations and overall insulin secretion as reflected by decreased integrated insulin and $\mathrm{C}$ peptide responses (Figs. 1,2). This decrease in insulin secretion was probably caused by the reduction in plasma glucose concentrations (Figs. 1,2) as well as the increase in sympathetic nerve activity (Fig. 3) elicited by exercise.

All the patients in our study were treated with diet only and were in good glycaemic control. We have recently shown that in postabsorptive Type II diabetic patient's glibenclamide adds to the hypoglycaemic action of prolonged submaximum exercise by increasing plasma insulin concentrations and, in turn, impairing hepatic glucose production [31]. Furthermore, we have shown that in the postabsorptive state the hypoglycaemic effect of prolonged submaximum exercise is more pronounced in Type II diabetic patients studied in poor compared with good glycaemic control (data unpublished). These observations suggest that the findings of the present study apply also to patients taking anti-diabetic drugs or being in poor glycaemic control or both. For final conclusions such patients must, however, be studied during high intensity exercise in the postprandial state.

The exercise induced overall reductions in glucose, insulin and $\mathrm{C}$ peptide responses to breakfast were identical in this study of intermittent high intensity exercise compared with our previous study of prolonged moderate continuous exercise [6] (Fig.4). The exercise protocol used in the previous study (45 min of exercise at $53 \pm 2 \% \dot{\mathrm{V}}_{\mathrm{O}_{2} \max }$ ) corresponded to the recommendations by the American Diabetes Association (ADA) regarding intensity and duration of exercise used in the treatment of Type II diabetic patients [32]. The identical effects on glucose homeostasis seen in the two studies indicate that Type II diabetic patients without coronary heart disease could also benefit from the many sports activities in which exercise is intermittent rather than continuous and in which peak intensity can attain $\dot{\mathrm{V}}_{\mathrm{O}_{2} \max }$. Different diabetic patients participated in this and the previous study but the two groups had identical age, sex, body weight, $\dot{\mathrm{V}}_{\mathrm{O}_{2} \max }$, diabetes duration and treatment [6]. The exercise protocols in the two studies were designed to be isocaloric and the total amount of work done was identical $\left(3553 \pm 395 \mathrm{~W} \cdot 46 \mathrm{~min}^{-1}\right.$ (present study) vs $3544 \pm 365$ watts $45 \mathrm{~min}^{-1}$ (previous study). Total carbohydrate combustion in the 46-min and 45-min exercise periods, roughly estimated from indirect calorimetry, was similar in the two studies, and corresponded to similar percentages of the carbohydrate taken with the breakfast meal (56 $\pm 4 \%$ (this study) vs $53 \pm 6 \%$ (previous study) $(p>0.05))$. Carbohydrate oxidation during the entire 4 -h period after breakfast ( $84 \pm 8 \mathrm{~g}$ (this) vs $78 \pm 8 \mathrm{~g}$ (previous study) was also similar in the two studies $(p>0.05)$. Furthermore, during the morning overall tissue glucose uptake and glucose appearance in plasma was identical in experiments with high intensity compared 
with experiments with moderate intensity [6] exercise $(p>0.05)$.

In this compared with our previous study [6], exercise protocols were isocaloric but differed in peak exercise intensity ( 98 vs $53 \% \dot{\mathrm{V}}_{\mathrm{O}_{2} \max }$ ). The similarity of responses to exercise in the two studies indicates that in the postprandial state overall energy expenditure is the major determinant of exercise induced changes in overall glucose homeostasis and insulin secretion in Type II diabetic patients. The peak intensity of exercise is not of major importance in this respect. In line with this conclusion is that in Type II diabetic patients identical improvements in postprandial glucose homeostasis can be obtained by exercise and isocaloric meal reduction, respectively [6]. A close coupling between effects of exercise on overall metabolic rate and glucose homeostasis, respectively, has also appeared from studies of healthy trained subjects $[33,34]$. It was shown that training induced improvements in responses to OGTT were abolished if glucose loads were adjusted for differences in daily carbohydrate intake between trained and untrained subjects [33]. Correspondingly, during ordinary living conditions trained subjects ate $130 \%$ more carbohydrate than sedentary subjects but integrated plasma glucose, $\mathrm{C}$ peptide and insulin concentrations were similar in the two groups [34].

In both the this and our previous study of Type II diabetic patients postprandial exercise had no effect on the responses of glucose, insulin, $\mathrm{C}$ peptide, NEFA and glycerol to a subsequent main meal (Figs. $1,2)$ [6]. Glycogen content in the vastus lateralis muscle was not measured in the earlier study [6] but was on exercise days in this study $27 \%$ lower immediately before lunch than in the basal state. So, it can be concluded that the decrease in muscle glycogen, which can be expected in association with postprandial exercise, is not sufficient to influence metabolic responses to a following main meal.

In conclusion, in contrast to findings in the postabsorptive state, postprandial severe exercise does not deteriorate glucose homeostasis. Such exercise reduces both glucose concentrations and insulin secretion. The effect of exercise seems closely related to total energy expenditure rather than to peak exercise intensity. Postprandial exercise does not influence glucose homeostasis during a subsequent main meal.

Acknowledgements. The authors thank L. Kall, V. Staffeldt, and R. Kraunsøe for skilled technical assistance. Financial support was received from the Danish Diabetes Association and the Danish National Research Foundation (j.nr. 504-514).

\section{References}

1. Minuk HL, Vranic M, Marliss EB, Hanna AK, Albisser AM, Zinman B (1981) Glucoregulatory and metabolic response to exercise in obese noninsulin-dependent diabetes. Am J Physiol. 240: E458-E464

2. Hubinger A, Franzen A, Gries FA (1987) Hormonal and metabolic response to physical exercise in hyperinsulinemic and non-hyperinsulinemic Type II diabetics. Diabetes Res 4: 57-61

3. Devlin JT, Hirshman M, Horton ED, Horton ES (1987) Enhanced peripheral and splanchnic insulin sensitivity in NIDDM men after single bout of exercise. Diabetes 36: 434-439

4. Koivisto VA and DeFronzo RA (1984) Exercise in the treatment of Type II diabetes. Acta Endocrinol Suppl 262: 107-111

5. Martin IK, Katz A, Wahren J (1995) Splanchnic and muscle metabolism during exercise in NIDDM patients. Am J Physiol 269: E583-E590

6. Larsen JJ, Dela F, Kjaer M, Galbo H (1997) The effect of moderate exercise on postprandial glucose homeostasis in NIDDM patients. Diabetologia 40: 447-453

7. Ivy JL, Frishberg BA, Farrell SW, Miller WJ, Sherman WM (1985) Effects of elevated and exercise-reduced muscle glycogen levels on insulin sensitivity. J Appl Physiol 59: 154-159

8. Richter EA, Garetto LP, Goodman MN, Ruderman NB (1984) Enhanced muscle glucose metabolism after exercise: modulation by local factors. Am J Physiol 246: E476-E482

9. Zorzano A, Balon TW, Goodman MN, Ruderman NB (1986) Glycogen depletion and increased insulin sensitivity and responsiveness in muscle after exercise. Am J Physiol 251: E664-E669

10. Kjaer M, Hollenbeck CB, Frey-Hewitt B, Galbo H, Haskell W, Reaven GM (1990) Glucoregulation and hormonal responses to maximal exercise in non-insulin-dependent diabetes. J Appl Physiol 68: 2067-2074

11. Gollnick PD, Piehl K, Saltin B (1974) Selective glycogen depletion pattern in human muscle fibres after exercise of varying intensity and at varying pedalling rates. J Physiol (Lond) 241: 45-57

12. Friedlander AL, Casazza GA, Horning MA et al. (1998) Training-induced alterations of carbohydrate metabolism in women: women respond differently from men. $\mathbf{J}$ Appl Physiol 85(3):1175-1186

13. Tarnopolsky LJ, MacDougall JD, Atkinson SA, Tarnopolsky MA, Sutton JR (1990) Gender differences in substrate for endurance exercise. J Appl Physiol 68: 302-308

14. Hother-Nielsen O, Beck-Nielsen H (1990) On the determination of basal glucose production rate in patients with Type II (non-insulin-dependent) diabetes mellitus using primed-continuous 3-3H-glucose infusion. Diabetologia 33: 603-610

15. Secher NH, Ruberg LN, Binkhorst RA, Bonde PF (1974) Maximal oxygen uptake during arm cranking and combined arm plus leg exercise. J Appl Physiol 36: 515-518

16. Ben-Jonathan N, Porter JC (1976) A sensitive radioenzymatic assay for dopamine, norepinephrine, and epinephrine in plasma and tissue. Endocrinology 98: 1497-1507

17. Galbo H, Holst JJ, Christensen NJ (1979) The effect of different diets and of insulin on the hormonal response to prolonged exercise. Acta Physiol Scand 107: 19-32

18. Dela F, Mikines KJ, Tronier B, Galbo H (1990) Diminished arginine-stimulated insulin secretion in trained men. $\mathrm{J}$ Appl Physiol 69: 261-267 
19. Mikines KJ, Farrell PA, Sonne B, Tronier B, Galbo H (1988) Postexercise dose-response relationship between plasma glucose and insulin secretion. J Appl Physiol 64: 988-999

20. Galbo H. (1983) Hormonal and metabolic adaptions to exercise. George Thieme Verlag, Stuttgart-New York

21. Galbo H, Christensen NJ, Mikines KJ et al. (1981) The effect of fasting on the hormonal response to graded exercise. J Clin Endocrinol Metab 52: 1106-1112

22. Pequignot JM, Peyrin L, Peres G (1980) Catecholaminefuel interrelationships during exercise in fasting men. $J$ Appl Physiol 48: 109-113

23. Montain SJ, Hopper MK, Coggan AR, Coyle EF (1991) Exercise metabolism at different time intervals after a meal. J Appl Physiol 70: 882-888

24. Jenkins AB, Furler SM, Bruce DG, Chisholm DJ (1988) Regulation of hepatic glucose output during moderate exercise in non-insulin-dependent diabetes. Metabolism 37: 966-972

25. Zinman B, Murray FT, Vranic M et al. (1977) Glucoregulation during moderate exercise in insulin treated diabetics. J Clin Endocrinol Metab 45: 641-652

26. Dela F, Mikines KJ, Sonne B, Galbo H (1994) Effect of training on interaction between insulin and exercise in human muscle. J Appl Physiol 76: 2386-2393

27. Vergauwen L, Hespel P, Richter EA (1994) Adenosine receptors mediate synergistic stimulation of glucose uptake and transport by insulin and by contractions in rat skeletal muscle. J Clin Invest 93(3):974-983

28. Ahlborg G, Bjorkman O (1987) Carbohydrate utilization by exercising muscle following pre-exercise glucose ingestion. Clin Physiol 7: 181-195

29. Pirnay F, Scheen AJ, Gautier JF, Lacroix M, Mosora F, Lefebvre PJ (1995) Exogenous glucose oxidation during exercise in relation to the power output. Int J of Sports Med 16: 456-460

30. Krzentowski G, Pirnay F, Luyckx AS, Lacroix M, Mosora F, Lefebvre PJ (1984) Effect of physical training on utilization of a glucose load given orally during exercise. Am J Physiol 246: E412-E417

31. Larsen JJ, Dela F, Madsbad S, Vibe-Peterson J, Galbo H (1999) Interaction of sulfonylurea and exercise on glucosehomeostasis in Type II diabetic patients. Diabetes Care, In press

32. Gordon NF (1995) The exercise prescription. In: Ruderman N, Devlin JT (eds) The Health Professional's Guide to Diabetes and Exercise. American Diabetes Association, Alexandria, Virginia

33. Dela F, Mikines KJ, Von Linstow M, Galbo H (1991) Effect of training on response to a glucose load adjusted for daily carbohydrate intake. Am J Physiol 260: E14-E20

34. Dela F, Mikines KJ, Von Linstow M, Galbo H (1991) Twenty-four-hour profile of plasma glucose and glucoregulatory hormones during normal living conditions in trained and untrained men. J Clin Endocrinol Metab 73: 982-989 